\title{
Mechanism Analysis of the Influence of Freeze-Thaw on the Damage and Debonding Evolution of Sandstone-Concrete Interface
}

\author{
Yanjun Shen $\mathbb{D}^{1,2,3}$ Tao Luo, ${ }^{1}$ Xin Wei $\mathbb{C}^{, 2,3}$ Xueting Li, ${ }^{2,3}$ Long Jin, ${ }^{4}$ Liangdong Wen, ${ }^{5}$ \\ Hui Peng, ${ }^{4}$ and Yanjun Ji ${ }^{1}$ \\ ${ }^{1}$ Shaanxi Key Laboratory of Safety and Durability of Concrete Structures, Xijing University, Xi'an 710123, China \\ ${ }^{2}$ Geological Research Institute for Coal Green Mining, Xi'an University of Science and Technology, Xi'an 710065, China \\ ${ }^{3}$ School of Geology and Environment, Xi'an University of Science and Technology, Xi'an 710054, China \\ ${ }^{4}$ State Key Laboratory of Road Engineering Safety and Health in Cold and High-Altitude Regions, \\ CCCC First Highway Consultants Co., Ltd, Xi'an 710075, China \\ ${ }^{5}$ CCCC Infrastructure Maintenance Group Co., Ltd., Beijing 100011, China
}

Correspondence should be addressed to Xin Wei; wx979202889@163.com

Received 8 December 2021; Accepted 17 January 2022; Published 15 February 2022

Academic Editor: Dongdong Ma

Copyright (C) 2022 Yanjun Shen et al. This is an open access article distributed under the Creative Commons Attribution License, which permits unrestricted use, distribution, and reproduction in any medium, provided the original work is properly cited.

\begin{abstract}
During tunnel construction in cold regions, the good adhesion of surrounding rock-lining interface is one of the important preconditions to evaluate the durability of tunnel lining. However, the repeated fatigue damage between rock and concrete due to the freeze-thaw action leads to debonding at the interface, which significantly affects the protective effect of shotcrete. Accordingly, based on the combination of sandstone-concrete as the object, through the development of sandstone-concrete interface freeze-thaw cycling test, and combining the nuclear magnetic resonance (NMR) test and scanning electron microscopy (SEM) analysis, the mechanism of debonding by freeze-thaw damage at the sandstone-concrete interface was systematically revealed. The conclusions drawn are as follows: (1) With the increase of freeze-thaw times, the content of micropores and macropores at the interface gradually increases, while the content of mesoporous gradually decreases. At the same time, the decrease of freeze-thaw temperature also aggravates the growth of interface cracks, and the freeze-thaw damage of interface is closely related to the minimum freeze-thaw temperature. (2) The damage of the sandstone side becomes more serious under multiple freeze-thaw actions. Concrete as a water retaining plate inhibits the migration of water to its interior, and a pot cover effect exists at the interface to provide better storage space for water accumulation. (3) The C-S-H group is the main source of the bond force of sandstone-concrete interface, and the freeze-thaw effect aggravates the fracture of the C-S-H group, which leads to the interface debonding. This study could provide an experimental basis and theoretical support for systematically recognizing the evolution mechanism of freeze-thaw damage and debonding of shotcrete in tunnels in cold regions.
\end{abstract}

\section{Introduction}

With the continuous progress of cold regions engineering construction, it is the premise to ensure the stability of the project to ensure that the surrounding rock-lining complex has good bonding performance in cold regions $[1,2]$. However, in cold regions, the bonding performance between soil and engineering body is often reduced due to repeated freeze-thaw actions, such as Qinghai G214 line
Jiang Luling, Yandang Mountain tunnel, etc. Because it is located in a high altitude cold regions, the repeated action of freeze-thaw may lead to rock-concrete interface cracks, debonding, fracture, and other problems [3-5], resulting in the concrete support not being fully effective. Therefore, the systematic study of the damage and debonding of rockconcrete interface induced by freeze-thaw and a full understanding of the internal mechanism of interface debonding have good guiding significance and reference 
value for further development of rock mass engineering protection problems in cold regions.

In the research on the failure performance of rockconcrete interface bond, under extreme environmental conditions, low temperature is often an important factor affecting the protection engineering and has an important influence on the bond property of rock-concrete interface. Xiang et al. $[6,7]$ carried out mechanical tests on rockshotcrete composite samples and studied the relationship between the number of freeze-thaw times and strain at the interface under freeze-thaw conditions. The results showed that the strain at the interface is proportional to the number of freeze-thaw times, and the rate of strain increase increases with the number of freeze-thaw times. Wang et al. [8] studied the shear strength of cement mortal-sandstone bonding interface under freeze-thaw conditions, and the results showed that, with the increase of freeze-thaw times, the shear strength of the interface decreased linearly and an obvious debonding phenomenon appeared at the interface. Qian et al. [9] studied the tensile strength and damage mode of composites formed by freeze-thaw cycles of 150 times and using splitting tests on two composites formed by ordinary silicate cement mortars, and the results showed that freeze-thaw cycles not only damage the material itself, but also degrade the weak bond interface. Shen et al. [10] conducted inclined shear tests on rock-concrete samples under different freeze-thaw times and proposed a new method to characterize shear fracture morphology based on image processing technology. Ma et al. [11] studied the bond behavior of concrete under different freeze-thaw effects and showed that the bond behavior of concrete decreases with the increase of freeze-thaw damage. At present, most of the above studies focus on the macroscopic fracture characteristics of the interface, and there are few studies on the damage and debonding of the mesoscopic and microscopic pores of the interface under freeze-thaw.

Secondly, in the research on the damage characteristics of freeze-thaw deterioration of rock and concrete, Yang et al. [12-14] used CT scanning technology to study the internal mesoscopic damage of sandstone under freezethaw action and found that rocks with higher porosity and water content showed significant internal damage and deterioration with the increase of freeze-thaw times. Zhang et al. [15] conducted CT scanning of sandstone after freezethaw times and studied the damage mode and pore development characteristics of sandstone in the freeze-thaw process. Argandoña et al. [16] and Liu et al. [17] studied the damage and deterioration characteristics of rocks under freeze-thaw times using computed tomography tests. G. Sokhansefat et al. [18] studied the crack propagation of cement mortar under freeze-thaw by X-ray computed microtomography. Some scholars [19-21] have conducted freeze-thaw tests on sandstone and studied the pore development of rock after freeze-thaw times by NMR. Cheng et al. [22] studied the porous damage of rock under freezethaw, carried out SEM and NMR technology tests on siltstone under different freeze-thaw times, and analyzed the distribution characteristics of the pore structure of siltstone. Liu et al. [23] used NMR technology to study the mechanical properties, pore size, and distribution of cement mortar in freeze-thaw times. Wang et al. $[24,25]$ used NMR to study natural pumice concrete after freeze-thaw times. Niu et al. [26] used NMR to study the pore structure changes in sandstone induced by freeze-thaw cycles and analyzed the microscopic morphology of sandstone in combination with SEM. The above study reflects that NMR technology has high practicability in the damage study of freeze-thaw rock or concrete. Although the above studies can better reflect the mesoscopic damage characteristics of rock freeze-thaw, most of them focus on the interface where rock or other single materials are combined, and relatively few studies focus on the interface where two materials are combined.

Therefore, in order to systematically understand the bond deterioration performance of rock-concrete interface in freeze-thaw environment, this paper carried out mesoscopic and microscopic studies on sandstone-concrete interface under different freeze-thaw actions to analyze the pore evolution law of interface; the damage deterioration and debonding evolution characteristics of the interface are clarified, so as to better reveal the freeze-thaw deterioration mechanism of interface.

\section{Mesoscopic and Microscopic Studies on Sandstone-Concrete Composites under Freeze-Thaw Conditions}

2.1. Preparation of Sandstone-Concrete Samples. Several sandstones (sedimentary rock) with less bedding were collected and transported to the processing plant. Electric rock cutting machine was used to cut and polish them into cuboid test blocks of $100 \mathrm{~mm}$ (length) $\times 100 \mathrm{~mm}$ (width) $\times$ $50 \mathrm{~mm}$ (height). C30 ordinary silicate concrete was selected, and the concrete cement label is PO42.5. The concrete was poured into the test mold and vibrated on the shaking table to increase the compactness. The finished concrete was placed in the shade, and the mold was removed after 24 hours of natural air drying. Then, the cube specimens were placed in a constant temperature of $20^{\circ} \mathrm{C}$ and humidity curing room with a temperature and humidity of $97 \% \mathrm{RH}$ for 28 days. The completed sample was cube with a side length of $100 \mathrm{~mm}$. A cylindrical sample of $\varphi 50 \mathrm{~mm} \times 100 \mathrm{~mm}$ was taken out from the vertical interface direction by a rock coring machine. A cylinder with a diameter of $5 \mathrm{~cm}$ and a thickness of $0.3-0.5 \mathrm{~cm}$ was cut by a rock cutter for microscopic determination. The sample preparation process is shown in Figure 1.

\subsection{Test Plan and Process}

2.2.1. Sandstone-Concrete Freeze-Thaw Cycles Test Scheme. In this test, the temperature was set to $\pm 10^{\circ} \mathrm{C}, \pm 15^{\circ} \mathrm{C}$, and $\pm 20^{\circ} \mathrm{C}$. To reduce the accidental error, three parallel samples were divided into each group of temperature. Sandstoneconcrete samples were subjected to different freeze-thaw cycles (i.e., 0, 5, 10, 15, and 20), and each freeze-thaw cycle 


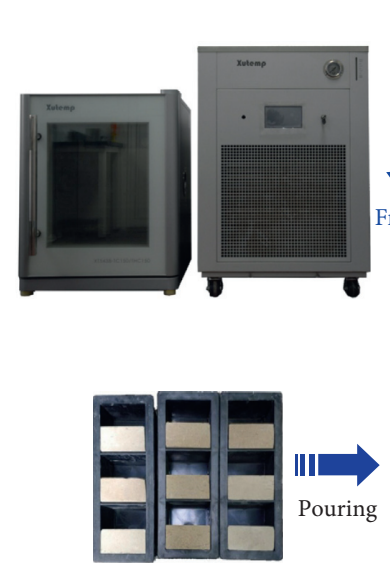

(a)
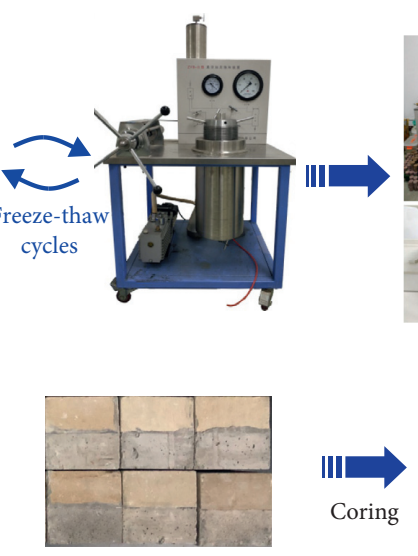

Sandstone-concrete

(b)

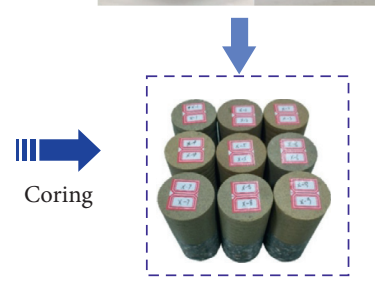

(c)

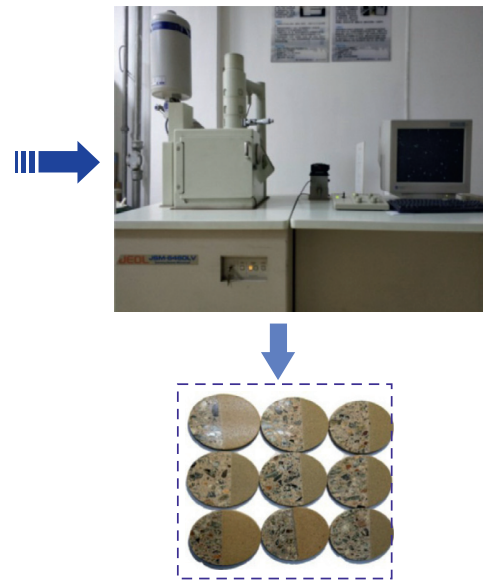

(d)

Figure 1: Test equipment and rock-concrete samples. (a) Low temperature automatic freeze-thaw tank. (b) Vacuum saturation device. (c) NMR microstructure analysis system. (d) SEM micromorphology analysis system.

was divided into two stages. The samples were frozen for $4 \mathrm{~h}$ and thawed for $4 \mathrm{~h}$, and the samples were subjected to repeated freeze-thaw until the set number of freeze-thaw times was reached. In the process, the samples were wrapped with a film to avoid water loss. After the freeze-thaw for 5 times, the samples need to be saturated again.

\subsubsection{Mesoscopic Test Scheme of Sandstone-Concrete} Interface. After the freeze-thaw cycle of sandstone-concrete samples, the stratified relaxation measurement of sandstoneconcrete under $\pm 20^{\circ} \mathrm{C}$ was mainly carried out by nuclear magnetic resonance (NMR). The SE-SPI layering sequence parameters were determined by adjusting the RF pulse frequency to match the intrinsic frequency through the FID sequence, i.e., finding the center frequency test. The specific parameters selected in the test are detailed in Table 1. The width of the NMR detection range was $150 \mathrm{~mm}$. In the test, the detection area was equally divided into 33 layers, and the width of each layer was $4.55 \mathrm{~mm}$. Among them the $-50 \sim 0$ layer is sandstone, the $0-50$ layer is concrete, and the $-1 \sim 1$ layer is interface.

2.2.3. Microscopic Test Scheme for Sandstone-Concrete Interface. Secondly, the sandstone-concrete samples with freeze-thaw temperature of $\pm 20^{\circ} \mathrm{C}$ were tested by scanning electron microscopy (SEM). The selected equipment is the low vacuum SEM produced by Japan electron optics company (type: JSM-6460V), with a resolution of $4.0 \mathrm{~nm}$, a maximum magnification of 300000 times, and an accelerating voltage of $0.5 \sim 30 \mathrm{kV}$. The test samples were put into the scanning chamber, and the sandstone-concrete interface was found in the case of small multiples. The flat and smooth area was selected, and the magnification was 100 times, 1000 times, 2000 times, and 5000 times successively, to observe and analyze the adhesion of ITZ and the microscopic morphology of interface crack extension. Sample preparation and test equipment are shown in Figure 1.

\section{Results}

3.1. Mesoscopic Damage Process Analysis of Sandstone-Concrete Composite Induced by Freeze-Thaw. Firstly, the freezethaw cycle tests of sandstone-concrete were carried out. Figure 2 shows the changes of mass and water content of sandstone-concrete under different freeze-thaw actions. By comparing the mass change of samples under the same freeze-thaw temperature, it can be found that the mass change rate of sandstone-concrete samples increases with the number of freeze-thaws, and the mass change rate in the late freeze-thaw period is greater than that in the early freeze-thaw period. This is because the internal pores of the sample are damaged under the action of frost heaving force.

At the same time, in the process of saturation, the saturation process allows further migration of water into the pores to supplement the pore cracking, resulting in repeated freeze-thaw damage, so the overall quality of the sample increases gradually. In addition, the growth rate of water content is different in different stages of freeze-thaw cycle. During the $0-5$ freeze-thaw times' phase, the water content increases slowly. During the 5-20 freeze-thaw times' phase, the water content increases rapidly. Secondly, with the decrease of freeze-thaw temperature, both the mass change rate and water content increase gradually. Under the freezethaw temperature of $\pm 20^{\circ} \mathrm{C}$, the mass change rate of samples is $20.08 \%$, and the average water content is $8.28 \%$, indicating that the damage of sandstone-concrete samples is significantly affected by the freeze-thaw temperature.

Secondly, in order to explore the damage evolution characteristics at the rock-concrete interface under freezethaw actions, it is particularly necessary to identify and track the pore changes at the sandstone-concrete interface under the freeze-thaw temperature of $\pm 20^{\circ} \mathrm{C}$ by $\mathrm{NMR}$, so as to reveal the fundamental causes of the interface damage.

The sandstone-concrete interface was tested by NMR stratification. Figure 3 shows the changes of pores at different positions of sandstone-concrete samples with the number of freeze-thaw times under the freeze-thaw environment of $-20^{\circ} \mathrm{C} \sim 20^{\circ} \mathrm{C}$. At different positions of sandstone- 


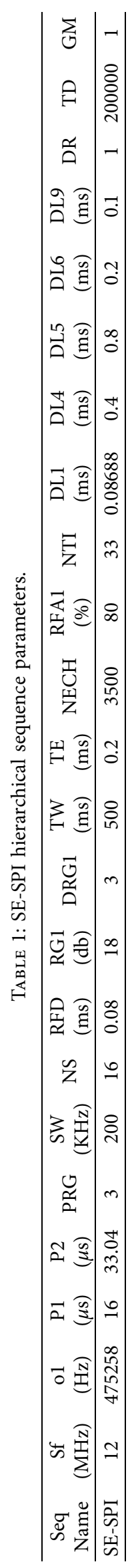




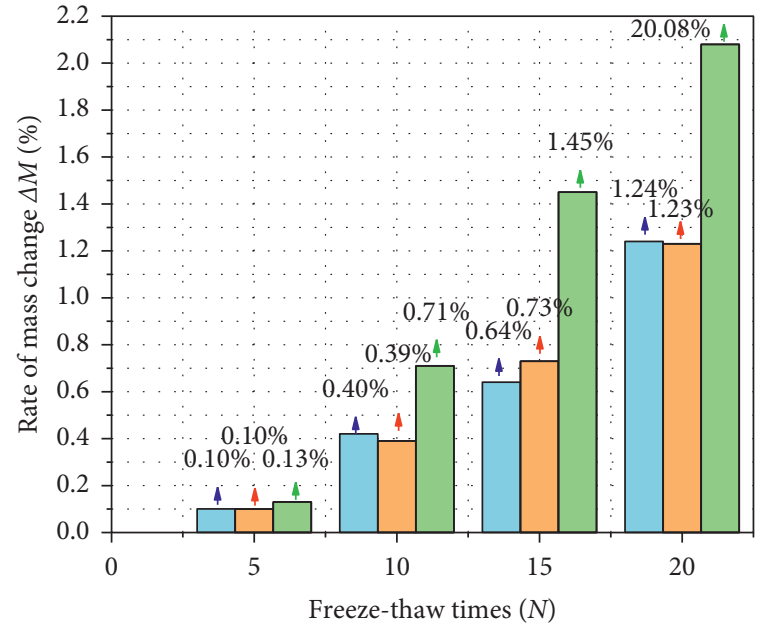

$\square$
$\square 10^{\circ} \mathrm{C}$
$\square$
$\pm 15^{\circ} \mathrm{C}$
$\square$
$\square 20^{\circ} \mathrm{C}$

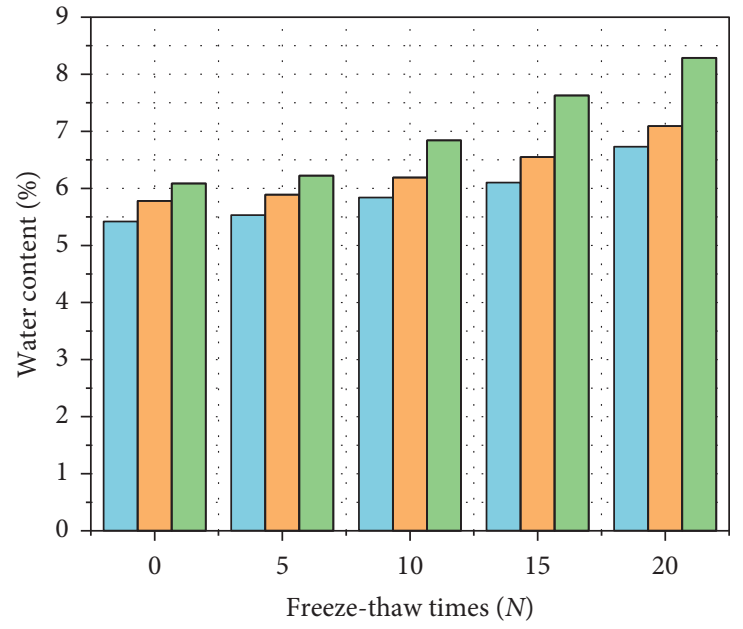

$\pm 10^{\circ} \mathrm{C}$
$\pm 15^{\circ} \mathrm{C}$
$\pm 20^{\circ} \mathrm{C}$

(a)

(b)

Figure 2: Change rate of sandstone-concrete under different freeze-thaw action. (a) Rate of mass change. (b) Water content.

concrete samples, the internal pore volume is clearly different. For sandstone and concrete, the difference of pore signal intensity between each position is 25000 a.u., within the scope. After 20 freeze-thaw times, the difference of pore signal intensity in sandstone increases to 50000 a.u., the concrete part is raised to about 40000 a.u., and the freezethaw cycles make the difference between sandstone and concrete more obvious. On the sandstone side, although the freeze-thaw cycle has an obvious influence on the pores in various positions, it mainly concentrates on the sandstone near the interface, and the water-gathering zone appears within $4.5 \mathrm{~mm}(-1 \sim 1$ layer $)$ in the sandstone near the interface.

Firstly, the pore distribution is divided into three categories according to previous studies [27, 28]. It is divided into the following: the micropores $\left(r<0.1 \mu \mathrm{m}, T_{2}<10 \mathrm{~ms}\right)$, mesopores $\left(0.1 \mu \mathrm{m}<r<1 \mu \mathrm{m}, 10 \mathrm{~ms}<T_{2}<100 \mathrm{~ms}\right)$, and macropores $\left(r>1 \mu \mathrm{m}, T_{2}>100 \mathrm{~ms}\right)$. Therefore, through the $T_{2}$ spectrum analysis of $-1 \sim 0$ layers at the interface, it can also be found that the pore distribution is bimodal. With the increase of freeze-thaw times, the micropores increase, the mesopores decrease, and the macropores increase, indicating that the interface pores expand and penetrate under the effect of freeze-thaw. At the same time, the pore is small in the 5th and 10th freeze-thaw times, but the pore is more significant after the 15th freeze-thaw, and the freeze-thaw action is mainly dominated by sandstone. In addition, the first layer is concrete layer, and the $T_{2}$ spectrum is mainly distributed in $0.2 \mathrm{~ms}-10 \mathrm{~ms}$. With the increase of the number of freeze-thaw times, the volume of microporous pores gradually increases, while the pore size of mesoporous increases. Therefore, at the ambient temperature of $-20^{\circ} \mathrm{C} \sim 20^{\circ} \mathrm{C}$, the existence of sandstone-concrete interface makes the sandstone-concrete duality show water enrichment zone during freeze-thaw cycle. The enrichment of water at the interface accelerates the damage and degradation of the interface and then accelerates the freeze-thaw damage at the interface.

For the analysis of the pore distribution at the interface and its adjacent spatial location in the freeze-thaw environment of $\pm 20^{\circ} \mathrm{C}$, color imaging was conducted here, as shown in Figure 4. The evolution law of the pore volume of sandstone-concrete samples with freeze-thaw times can be clearly demonstrated. At the same time, the irregularity of pore changes under freeze-thaw can be observed clearly. The total pore volume of sandstone is larger than that of concrete. With the increase of the number of freeze-thaw, the pore distribution range and the peak value of nuclear magnetic signal intensity of sandstone near the interface are different from those of other positions. Compared with other positions, the coverage of pores near the interface increases, and the development of macropores becomes more obvious.

3.2. ITZ Microcosmic Debonding Process Analysis of Sandstone-Concrete Composites Induced by Freeze-Thaw. It can be seen from the above microscopic test results that a weak area of water accumulation occurs at the rock-concrete interface under freeze-thaw action, which leads to serious damage and deterioration with the increase of freeze-thaw action and is a key area to induce interface debonding. Therefore, it is an effective means to further reveal the mechanism of interface freeze-thaw deterioration by analyzing the descaling process from the microscopic perspective.

The bonding process of rock-concrete interface is a complex physical and chemical process. Due to the different characteristics of rock and concrete materials, ITZ is easy to appear in the sandstone-concrete contact area in cementation process; while the interfacial moisture accumulation 

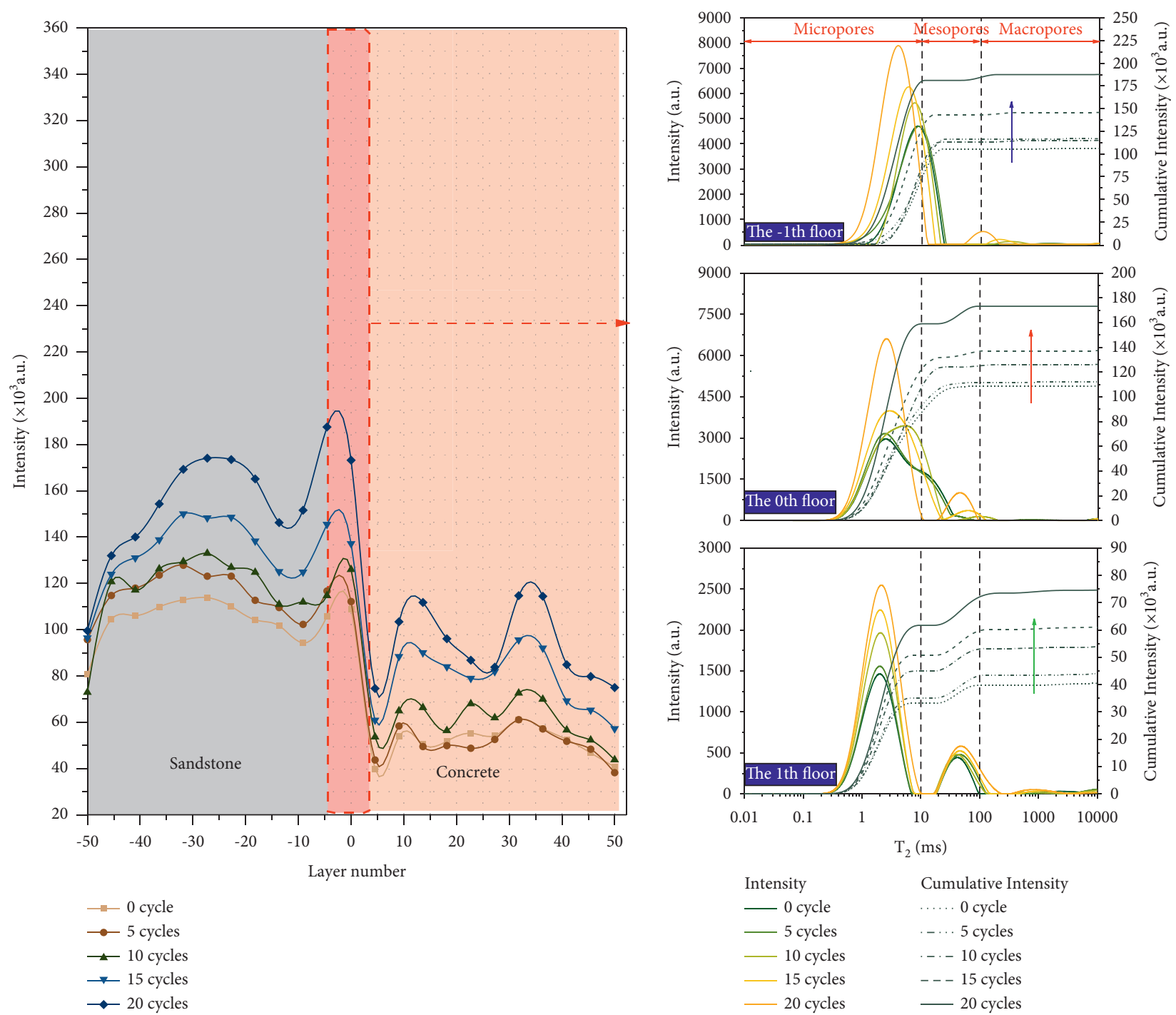

FIGURE 3: Sandstone-concrete pore distribution and interfacial $T_{2}$ spectrum under different freeze-thaw times.

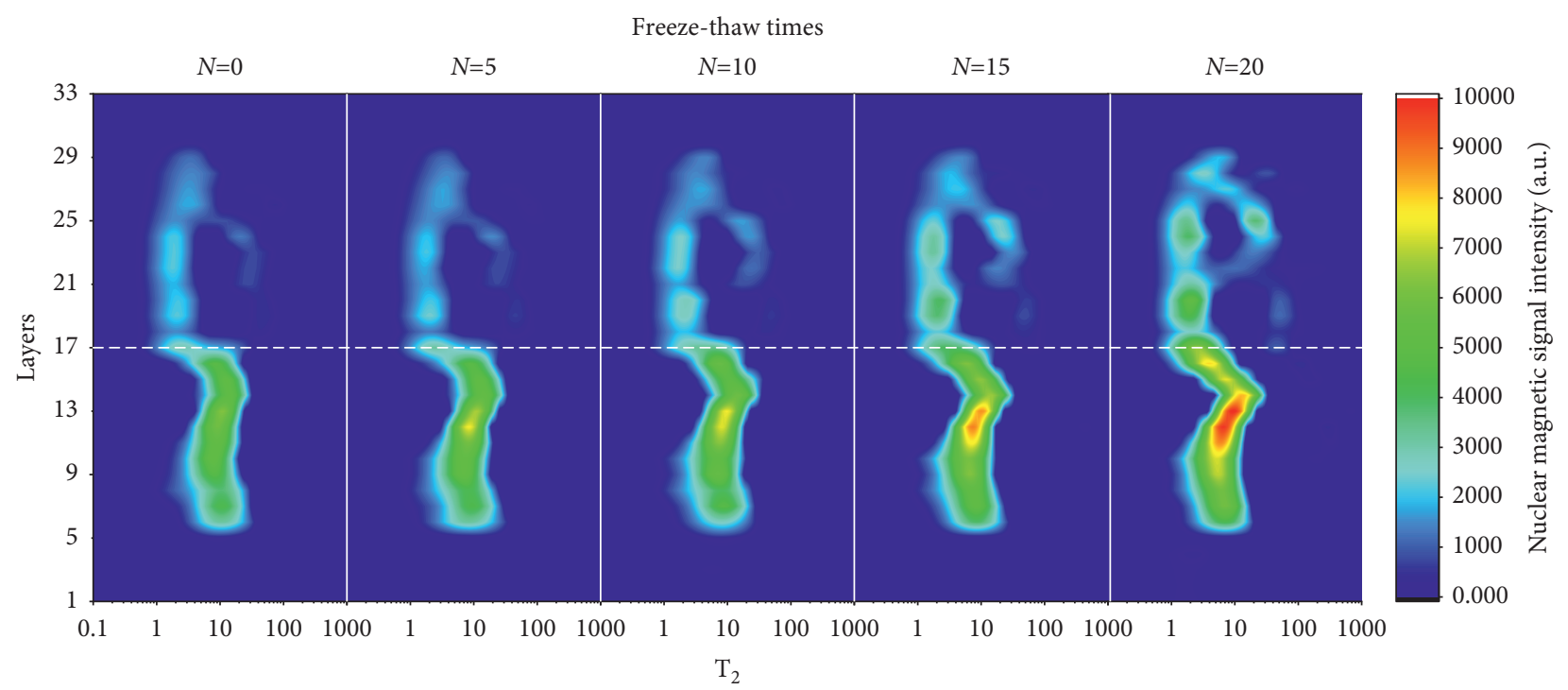

FIGURE 4: Color map of pore distribution of sandstone-concrete sample. 
area mostly occurs within the interface ITZ, the ITZ is not easily distinguishable homogeneous zone, but a region where the structure between each mineral particle is changing. ITZ can be divided into macrointerface transition zone and microinterface transition zone according to the difference of analysis scale. Among them, the macroscopic interface transition zone refers to the interface formed by two-phase contact between sandstone and concrete. The existence of the interface will affect the strength, stiffness, and durability of sandstone-concrete duality. Micro-ITZ refers to the interface that is not a "face," but a "layer" ("zone," "band") with a certain width [29]. The physical and mechanical properties of the "layer" are quite different from those of the cement slurry substrate. The basic trend of the physical and mechanical properties of the "layer" is that, with the increase of the distance from the aggregate surface, the microscopic mechanical changes first decrease, then increase, and then stay the same, presenting a typical " $U$ " shape characteristic, so it is called the "transition layer," and its width is about $15-120 \mu \mathrm{m}$ [30-34]. Therefore, the degradation process of ITZ under freeze-thaw can effectively reveal the mechanism of water migration on the interface.

The microstructure of sandstone-concrete interface under different freeze-thaw times and different freeze-thaw temperatures was scanned by SEM to observe the crack propagation at the interface, as shown in Figure 5. It can be found that no obvious cracks were caused on the sandstoneconcrete interface for 5 freeze-thaw times and when the sandstone-concrete interface was cracked to different degrees after 10 freeze-thaw times. With the increase of freezethaw cycles, the fatigue damage of sandstone-concrete interface increases, and the hydration products connecting the weakest interface between sandstone and concrete are destroyed; as a result, the expansion of interfacial cracks along the whole interface and some particles spall off.

By comparing the crack growth of sandstone-concrete interface under different temperature gradients and the same freeze-thaw times, it can be seen that, in $\pm 10^{\circ} \mathrm{C}$ low temperature group, cracks start to develop and their morphology gradually expands to the fine wire, but the cracking effect is not obvious. With the decrease of freezing temperature, the difference between $\pm 15^{\circ} \mathrm{C}$ group and $\pm 20^{\circ} \mathrm{C}$ group increased significantly, and the phenomenon of white flocculent debris and particle spalling gradually appeared, which was mainly manifested in the length, width, and strike morphology of the interfacial cracks.

Observe the changes of sample surface topography under the freezing-thawing temperature of $\pm 20^{\circ} \mathrm{C}$ and the freeze-thaw times of 20. Take 100, 1000, 2000, and 5000 times, respectively, to observe the sample area. It can be seen from Figure 6 that there is an obvious interface between sandstone and concrete. There is an ITZ in this region, which is also reflected in the experimental results. In the freeze-thaw cycle, the volume will increase by $9 \%$ during the process of changing from water phase to ice. When the volume increases, ice in the pores will produce frost heaving force on sandstone-concrete interface and cracks occur at the interface. It can be seen that the hydration products are filled in the cracks of ITZ. The fillers are mainly $\mathrm{CH}$ crystals and C-S-H gel, in which C-S-H gel has a spherical, floc like structure and a relatively smooth surface. $\mathrm{CH}$ crystals have a large crystal size and cake and petal like structure and appear with enrichment and orientation arrangement. It indicated that these cracks are the damage to sandstone-concrete interface caused by freezethaw cycle. In addition, the micropores on the rock surface extend to a certain range of the interior of the rock mass, and the shape of the cementitious materials is roughly like a needle-like structure, which is similar to a network interlocking together. In previous studies, it has been proved that C-S-H cementitious groups extend radially and bond concrete with other materials well through the exchange of chemical bonds.

The above test results reflect the ITZ cracking of sandstone-concrete interface under different freeze-thaw times. Meanwhile, the morphology of sandstone-concrete interface transition zone at different multiples shows that the interface is a special weak surface. According to the research results at home and abroad, the water in the sample will undergo water-ice phase transformation, and the volume expansion will produce frost heave force, which will lead to the increase and extension of cracks in the sample. Under normal temperature, all the ice in the sample is turned into water. As the sample is completely saturated, water will enter the new cracks or pores. When entering the next freezing process, new cracks will be produced due to the influence of frost heaving force. With the repeated freeze-thaw test, the length, width, and depth of cracks increase continuously, and form a continuous crack. The freezing process spreads from the outside to the inside, with internal cracks spreading to the surface while the external temperature remains negative.

From the perspective of interface macrocrack expansion, the compactness of concrete and sandstone materials themselves is relatively low, and the water content is relatively large. In the saturated state, repeated freeze-thaw tests are equivalent to repeated loading and unloading tensile tests inside the sample. When the number of freeze-thaw cycles is large enough, and the frost heave force is greater than the bonding force of hydration products on both sides of the interface, new microcracks will appear at the interface or the original microcracks will increase and extend. From the observation of sandstone and concrete surface, it can be seen that the crack expansion on the sample surface is not generated along a straight line but extends irregularly, but the crack at the interface is along and the crack direction is mostly parallel to the axis of the interface. This phenomenon can fully explain that, under a certain number of cycles, the frost heaving force generated by freeze-thaw is greater than the cohesive force generated by the cement hydration products at sandstone-concrete interface, and thus the debonding occurs.

Therefore, cracks are easily generated on the sandstoneconcrete interface and are most likely to be generated and spread from this region, which acts as a fast channel for ion migration and solution penetration, so these interfacial transition zones are considered the weakest areas of sandstone-concrete samples. 

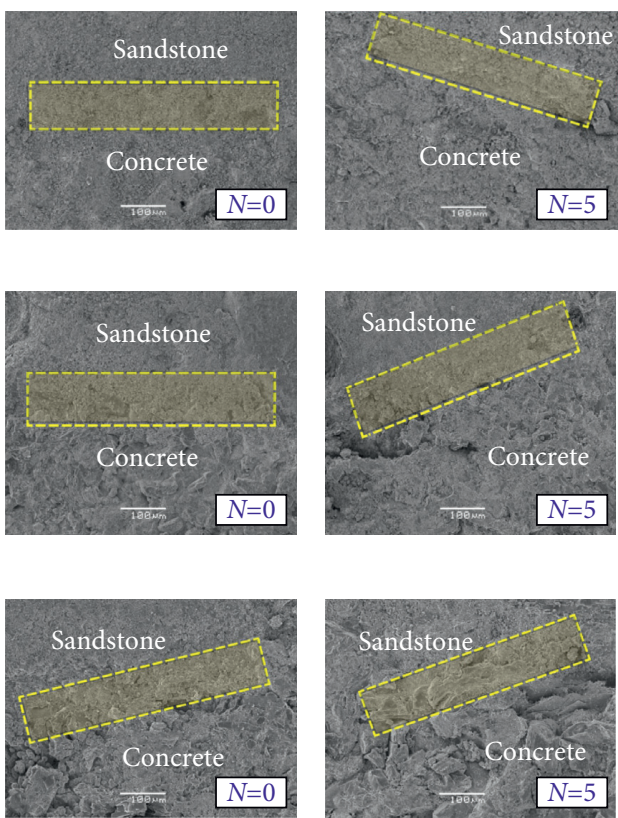
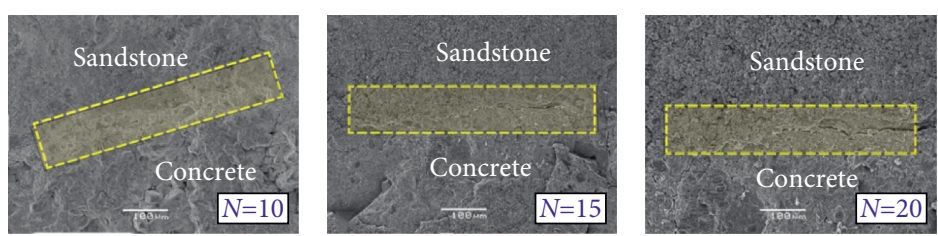

(a)
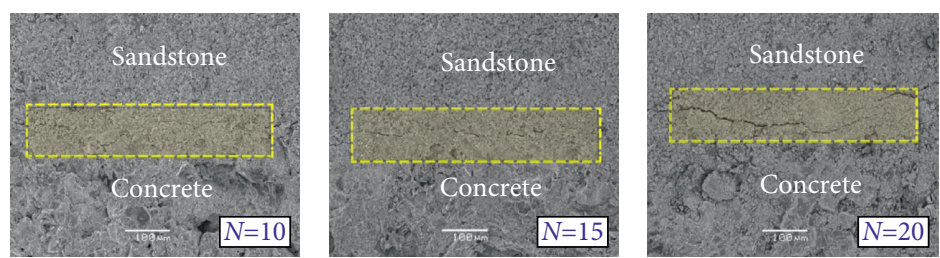

(b)
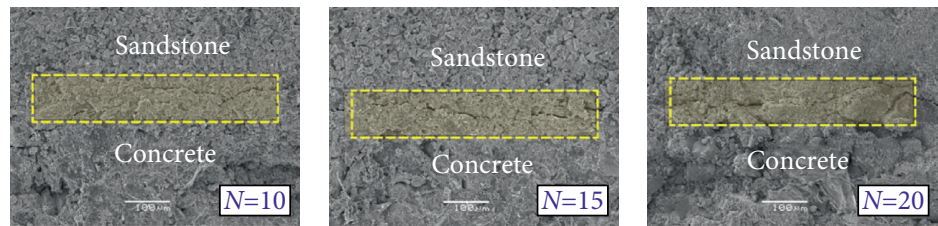

(c)

FIGURE 5: Micromorphology of sandstone-concrete interface under different freeze-thaw times.
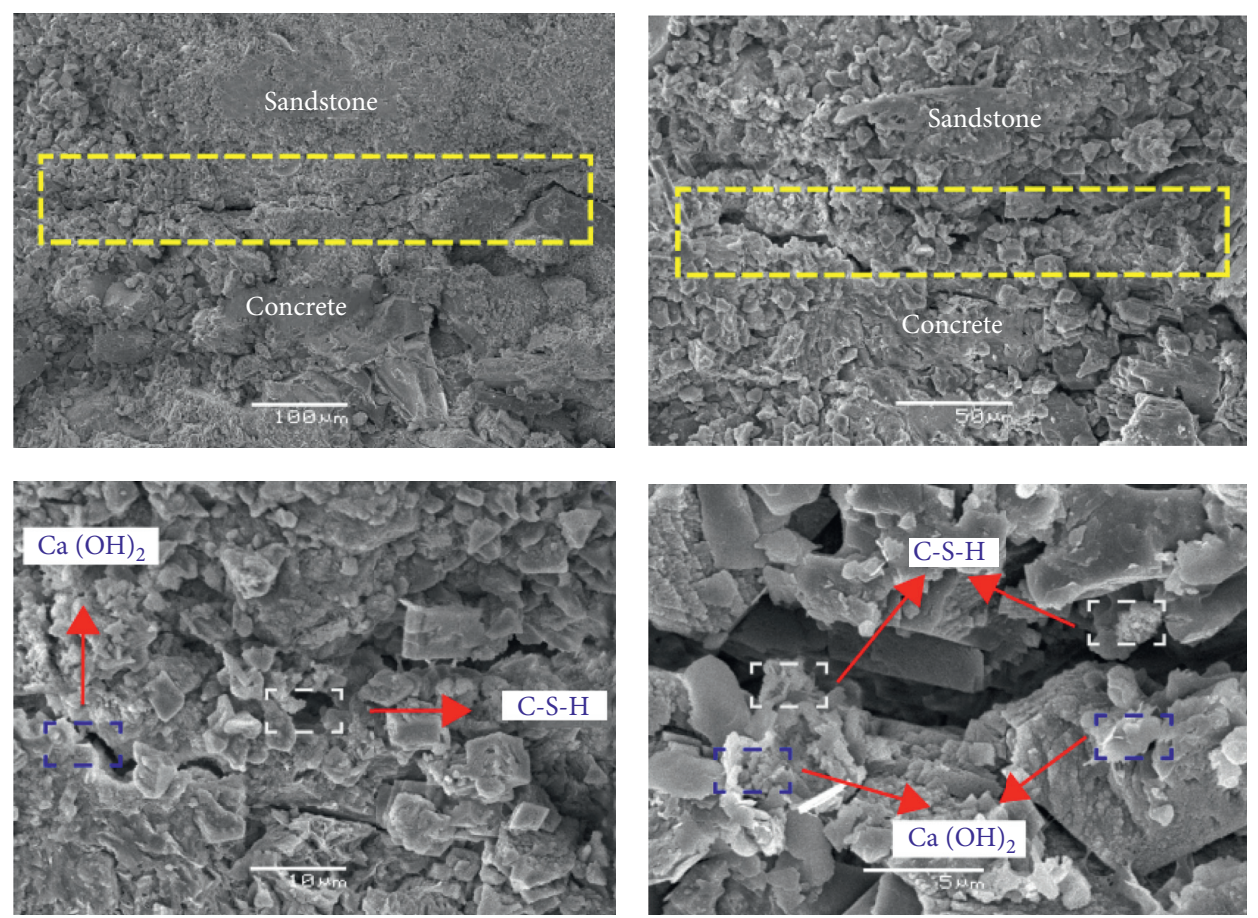

FIgURE 6: Morphologies of sandstone-concrete interface transition zone at different multiples.

\section{Mechanism of Damage Degradation of Sandstone-Concrete Interface Induced by Freeze-Thaw}

It is found that freeze-thaw effect has a significant effect on the bonding property of rock-shotcrete by studying the interface bonding property of sandstone-concrete materials, in which the hydrothermal migration is the external cause and the interface properties are the inducement. All factors jointly promote the debonding fracture of the interface. Therefore, the mechanism of rock-concrete interface debonding fracture is mainly revealed from the following aspects.

4.1. Debonding Morphology of Sandstone-Concrete under Different Freeze-Thaw Times. The degree of freeze-thaw damage is analyzed from the interface topography of sandstone-concrete. Figure 7 is the interface debonding 


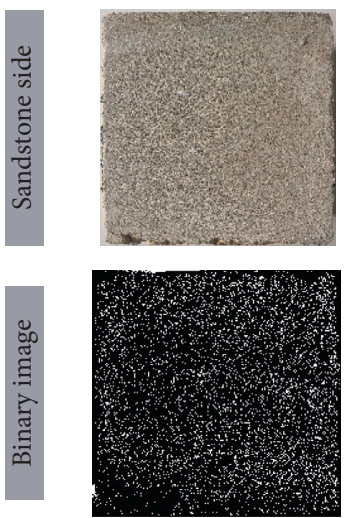

$N=0 n=94.07 \%$
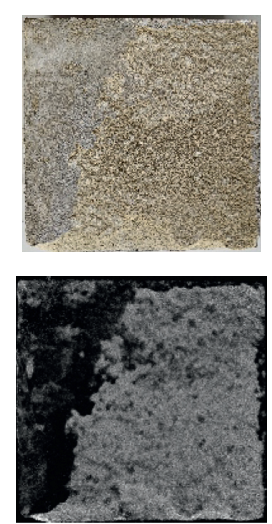

$N=5 n=36.74 \%$
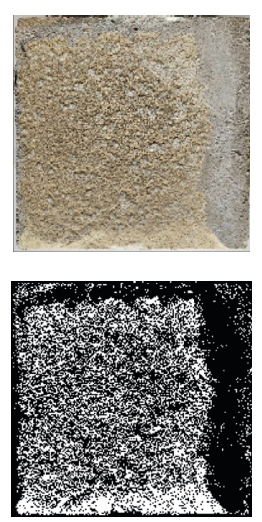

$N=10 n=29.85 \%$
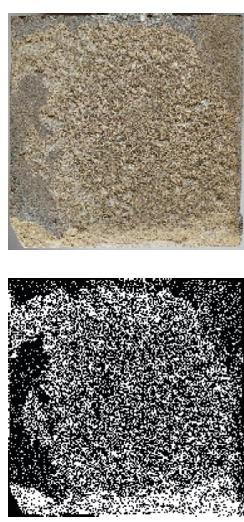

$N=15 n=21.54 \%$
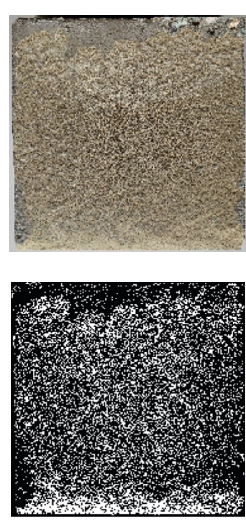

$N=20 n=17.65 \%$

FIGURE 7: Topography of sandstone-concrete interface under different freezing-thawing times.

fracture topography of sandstone-concrete at the freezethaw temperature of $\pm 20^{\circ} \mathrm{C}$ with different freeze-thaw times. It can be seen that there is concrete adhesion on the sandstone side, and the amount of concrete adhesion gradually decreases. It can be found that, with the increase of freeze-thaw times, the debonding failure of sandstoneconcrete interface occurs on the sandstone side, and the freeze-thaw cycle aggravates the deterioration degree of interface debonding of materials. This is because there is a great difference in the strength of the two materials, the freeze-thaw deterioration effect on the sandstone side is significantly higher than that on the interface, which leads to the interface cracks of sandstone-concrete deflecting to the sandstone side in the later stage, and the bond performance is significantly reduced. Therefore, the damage debonding and deterioration performance of rock-concrete composite interface is also controlled by the strength of the material itself.

\subsection{Mesoscopic Damage Mechanism of Hydrothermal Transfer} at Sandstone-Concrete Interface. From the NMR test results, it can be seen that the damage and debonding process at the sandstone-concrete interface is directly related to the migration of water and the water-ice phase change during the freeze-thaw process. When there is a large amount of water in and around the rock, it is easier to produce frost heaving in the rock at low temperature due to the expansibility of the rock. Assuming that the internal pores of sandstone are saturated, the water in sandstone freezes into ice under a low temperature environment, and thus $9 \%$ volume expansion is generated by water-ice transformation in sandstone, resulting in a larger frost heaving force, which causes the pore surface to bear frost heaving stress. For different pore sizes, there are differences in the phase transformation of water ice at low temperature. The pore with larger pore diameter contains more free water, while the pore with smaller pore diameter contains less free water. For free water in pores, the low temperature required for the water-ice phase transformation is less different than that of free water in the natural environment. However, the pores with relatively small pore size and the contact between water and rock in large pores often contain more bound water. In the process of water-ice phase transformation, the bound water usually releases more energy when frozen, and the relaxation time of water-ice phase transformation is longer, resulting in the lower freezing point of the bound water [35]. Therefore, when the temperature is higher than $-20^{\circ} \mathrm{C}$, there is obviously unfrozen water in the pores. The unfrozen water inside the sandstone will produce an obvious "hydraulic fracturing effect" on the rock skeleton under the action of ice pressure, as shown in Figure 8(a). Due to the effect of hydraulic fracturing, there are significant hydraulic gradient differences in the pores. At the same time, due to the connectivity of unfrozen water, unfrozen water is inevitably driven by volume expansion under the action of water-ice phase transformation, resulting in the water migration phenomenon, as shown in Figure 8(b).

At the same time, the critical failure stress of concrete is larger than that of sandstone. During the freezing process, the energy of the pores near the interface is concentrated in the sandstone, and the pores near the interface begin to fracture in the sandstone. The fracture behavior of the sandstone tip provides a way for the release of energy in the pores. Further analysis shows that concrete acts as a water baffle, and the pot cover effect appears at the interface under freeze-thaw. Due to the distribution of pores in sandstone, the interfacial cracks are connected and intersected, which further aggravates the interface deterioration.

However, in sandstone, there is no interface effect, and the water pressure caused by hydraulic fracturing is evenly distributed in all directions of the pores, so there is no optimal path for stress release. The water pressure at each potential crack location is averaged, and the water pressure is smaller than that of concrete as a water baffle. Therefore, the hydraulic fracturing effect near the interface is more obvious, and the water enrichment phenomenon appears at the interface during the freeze-thaw cycle. In addition, due to the infiltration of cement slurry, calcium silicate hydrate (C-S$\mathrm{H}$ ) is formed, which has a bonding stress with sandstone particles. Compared with sandstone, liquid water is more difficult to migrate into concrete. As a result, water gradually migrates towards the interface. 


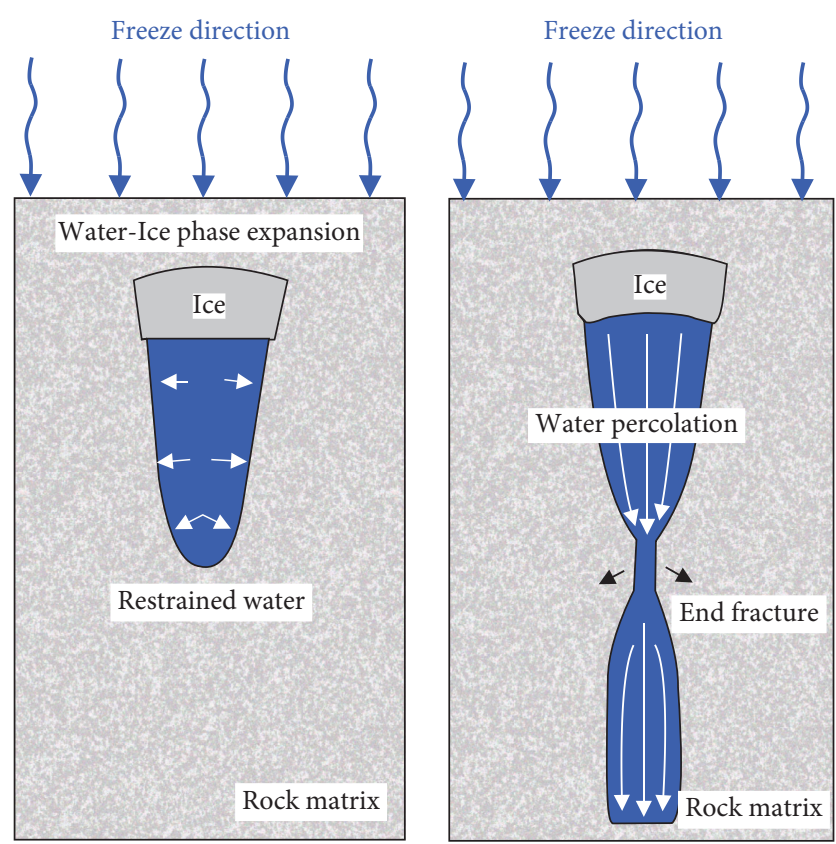

(a)

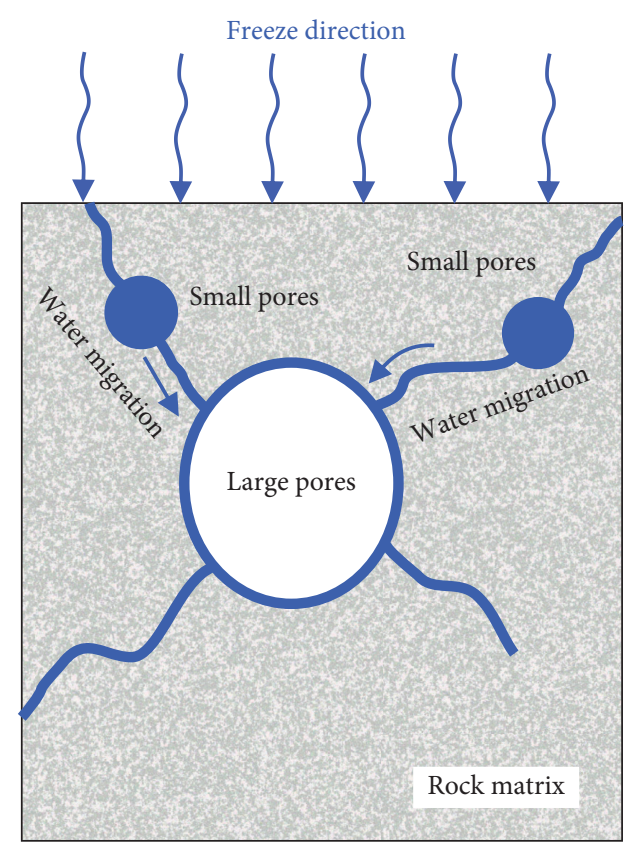

(b)

FIGURE 8: Generalized pore water migration at low temperature. (a) Volumetric expansion induced hydraulic fracturing effect. (b) Small pore induced water migration.

\subsection{Microcosmic Debonding Mechanism of Sandstone-Con-} crete Interface Transition Zone. One of the main factors of interface debonding is the decrease of bonding force caused by freeze-thaw. The bonding force is caused by the adhesion of concrete to the rock surface to resist the relative sliding of the interface, and the C-S-H gel group produced by the hydration of cement to the rock wall is the main source of the bonding force [36]. In the rock material, the rock surface will show a rise and fall and small micropores; when concrete and rock surface contact together, cement mud will penetrate into the rock surface micropores and continue to go deep, in the concrete slurry solidification, making concrete and rock firmly occlude together.

Due to the difference of material properties between sandstone and concrete, ITZ is the area where damage and fracture of sandstone and concrete occur first. Therefore, the rock-concrete ITZ can be roughly divided into three layers, which are embedded zone, permeable zone, and capillary zone, respectively [37, 38], as shown in Figure 9. The first layer is close to the sandstone interface, also known as the embedded zone, which is mainly characterized by the presence of needle-like and spiny crystals, calcium hydroxide crystals, and a small amount of C-S-H gel in the pores or microcracks of the sandstone. These crystals reach out to the interface transition zone at different angles, as these crystals will develop continuously against the sandstone surface, thus continuously exerting a pushing force on the cement slurry, making the longitudinal depth of the ITZ zone increasing, and this layer is also the gathering area of chemical products, pores, and cracks. The number and shape of the crystals in the weak effect layer are roughly the same as those in the reaction layer. The size of the crystals is smaller than that in the reaction layer, but the hydration products in this layer are cross dense and the bonding strength is stronger than that in the reaction layer. Therefore, for sandstoneconcrete duality, it is easy for the sandstone surface to absorb the moisture of grout inside concrete, $\mathrm{C}-\mathrm{S}-\mathrm{H}$ gel is easy to immerse into the rock and undergo hydration reaction to produce the "root pile" effect, and the "rockconcrete" interface bonding force is formed through the C-S-H gel embedded bite force [39].

Therefore, from the interface microscopic perspective, the "transition layer" of sandstone-concrete samples is due to the migration of water molecules in concrete to the interface surface of sandstone, and the water-cement ratio gradually decreases. The closer it is to the interface surface of sandstone, the more easily the hydrated products are generated; the crystals have stronger orientation and larger size, and the degree of orientation and crystal size decrease with the increase of the distance from the interface surface of sandstone. From the perspective of damage-fracture mechanics, this is the place where defects accumulate and the area where damage and fracture of sandstone-concrete samples first occur. 


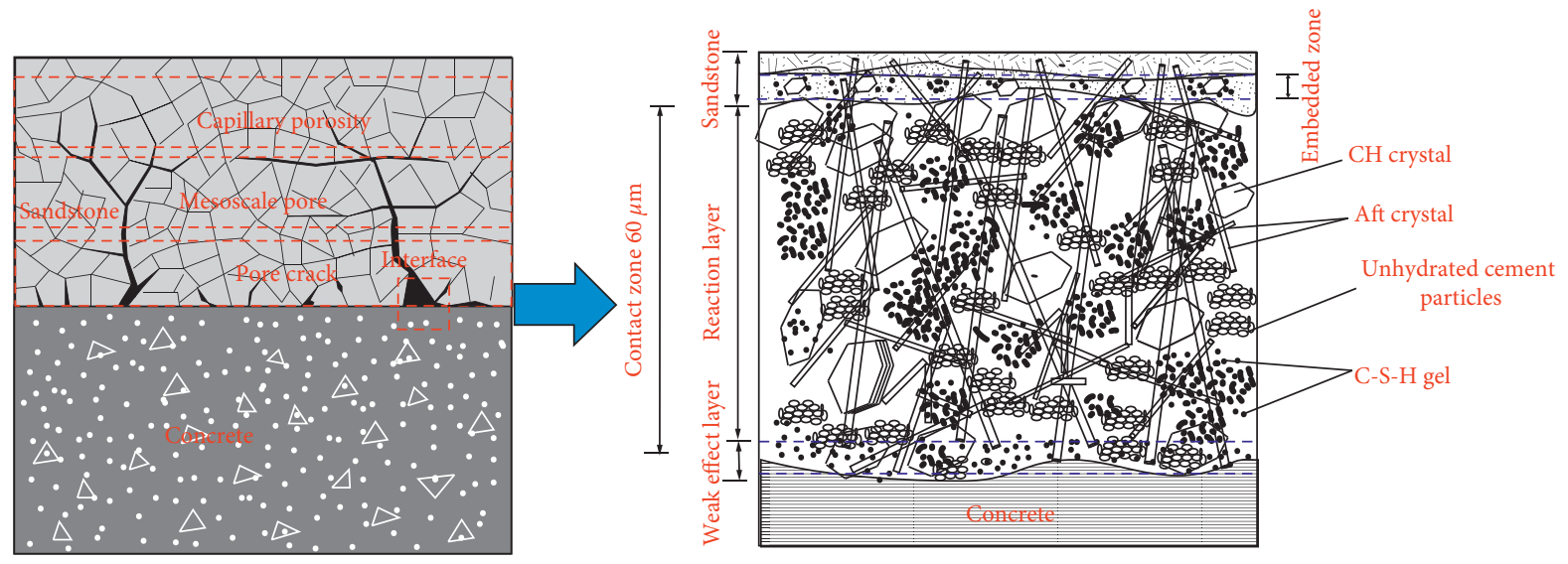

FIgURe 9: Microscopic model of the ITZ.

\section{Conclusion}

In this paper, sandstone-concrete samples were taken as the research objects; the mesoscopic and microscopic tests of sandstone-concrete under different freeze-thaw times and freeze-thaw temperature were carried out. The characteristics of interfacial water migration and evolution were determined, and the microscopic damage mechanism of sandstone-concrete interface was revealed. The main conclusions were as follows:

(1) It can be found by NMR test that the pore size near the interface shows an increase in micropores, a decrease in mesopores, and a significant increase in macropores with the increase of freeze-thaw times. At the same time, the pores increase slowly in the early stage of freeze-thaw, and the small pores increase rapidly in the later stage of freezethaw.

(2) The permeability of concrete is clearly less than that of sandstone, and the porosity content of sandstone is large with the increase of freeze-thaw times. The unfrozen water in the interfacial pores migrates to the sandstone side under the action of frost heaving force, the cracks selectively extend into the sandstone, the water accumulates at the interface, and the concrete acts as a water baffle, resulting in interface freeze-thaw debonding.

(3) Under freeze-thaw cycles, the hydration products were found to fill the cracks in the ITZ. The fillers were mainly $\mathrm{CH}$ crystals and $\mathrm{C}-\mathrm{S}-\mathrm{H}$ gel. When cracks occur, the hydration products in the ITZ break down, decrease, and disappear. Freeze-thaw induced the fracture of C-S-H group in the interfacial immobilized zone, which directly led to the decrease of bonding strength.

\section{Data Availability}

Some or all data, models, or code that support the findings of this study are available from the corresponding author upon reasonable request.

\section{Conflicts of Interest}

On behalf of all authors, the corresponding author states that there are no conflicts of interest.

\section{Acknowledgments}

This work was supported by the Foundation of Shaanxi Key Laboratory of Safety and Durability of Concrete Structures, Xijing University (Grant no. XJKFJJ201802), and the Shaanxi Province New-Star Talents Promotion Project of Science and Technology (Grant no. 2019KJXX-049).

\section{References}

[1] H. P. Xie, ZH. Chen, C. Yi, and H. W. Zhou, "Research on deformation and failure of interface based on interaction between structural body and Geo-body," Chinese Journal of Rock Mechanics and Engineering, vol. 27, no. 9, 2008.

[2] K. Lo, T. Ogawa, B. Lukajic, and D. D. Dupak, "Measurements of strength parameters of concrete-rock contact at the damfoundation interface," Geotechnical Testing Journal, vol. 14, no. 4, pp. 383-394, 1991.

[3] W. Ma and DY. Wang, "Studies on frozen soil mechanics in China in past 50 years and their prospect," Chinese Journal of Geotechnical Engineering, vol. 34, no. 4, pp. 625-640, 2012.

[4] T. Wang, G. Zhou, J. Wang, and L. Yin, "Stochastic analysis of uncertainty mechanical characteristics for surrounding rock and lining in cold region tunnels," Cold Regions Science and Technology, vol. 145, pp. 160-168, 2018.

[5] X. X. Wei, B. Zheng, and R. J. Wang, "Frost damage mechanisms and anti-freezing measures for tunnels in a seasonally frozen soil region," Modern Tunnelling Technology, vol. 55, no. 2, pp. 44-50, 2018.

[6] W. Xiang, Y. Wang, H. L. Jia, and Y. Guo, "Model test study of rock-shotcrete layer structure under freezing-thawing cycles," Chinese Journal of Rock Mechanics and Engineering, vol. 30, no. 9, pp. 1819-1826, 2011.

[7] W. Xiang and X. Liu, "Experimental study of mechanical properties of combined specimen with rock and shotcrete under freezing-thawing cycles," Chinese Journal of Rock Mechanics and Engineering, vol. 29, no. 12, pp. 2510-2521, 2010. 
[8] W. Wang, X. Yang, S. Huang, D. Yin, and G. Liu, "Experimental study on the shear behavior of the bonding interface between sandstone and cement mortar under freeze-thaw," Rock Mechanics and Rock Engineering, vol. 53, no. 7, 2019.

[9] Y. Qian, D. Zhang, and T. Ueda, "Interfacial tensile bond between substrate concrete and repairing mortar under freeze-thaw cycles," Journal of Advanced Concrete Technology, vol. 14, no. 8, pp. 421-432, 2016.

[10] Y. J. Shen, H. W. Yang, J. M. Xi, Y. Yang, Y. Z. Wang, and $\mathrm{X}$. Wei, "A novel shearing fracture morphology method to assess the influence of freeze-thaw actions on concrete-granite interface," Cold Regions Science and Technology, vol. 169, p. 102900, 2019.

[11] Z. Ma, F. Zhu, and G. Ba, "Effects of freeze-thaw damage on the bond behavior of concrete and enhancing measures," Construction and Building Materials, vol. 196, pp. 375-385, 2019.

[12] G. S. Yang, Q. S. Zhang, and Y. B. Pu, "Preliminary study on meso-damage propagation characteristics of rock under condition of freezing temperature," Rock and Soil Mechanics, vol. 25, no. 9, pp. 1409-1412, 2004.

[13] G. S. Yang, Q. S. Zhang, and Y. B. Pu, "A study on the damage propagation characteristics of rock under the frost and thaw condition," Chinese Journal of Geotechnical Engineering, vol. 26, no. 6, pp. 838-842, 2004.

[14] G. S. Yang and H. Liu, "Study on the rock damage characteristics based on the technique of CT image processing," Journal of China Coal Society, vol. 32, no. 5, pp. 463-468, 2007.

[15] H. M. Zhang, H. Wang, J. F. Zhang, S. F. Cheng, and H. W. Zhou, "Analysis of meso-damage characteristics of freeze-thaw rock on CT scale," Journal of Liaoning Technical University, vol. 39, no. 245, pp. 51-56, 2020.

[16] V. G. Ruiz, D. Argandoa, A. R. Rey, C. Celorio, L. M. S. D. Río, and J. Llavona, "Characterization by computed X-ray tomography of the evolution of the pore structure of a dolomite rock during freeze-thaw cyclic tests," Physics and Chemistry of the Earth, Part A: Solid Earth and Geodesy, vol. 24, no. 7, pp. 633-637, 1999.

[17] B. Liu, Y. Ma, N. Liu, Y. Han, D. Li, and H. Deng, "Investigation of pore structure changes in Mesozoic water-rich sandstone induced by freeze-thaw process under different confining pressures using digital rock technology," Cold Regions Science and Technology, vol. 161, pp. 137-149, 2019.

[18] G. Sokhansefat, M. Moradian, M. Finnell et al., "Using X-ray computed tomography to investigate mortar subjected to freeze-thaw cycles," Journal Pre-Proof, vol. 108, Article ID 103520, 2020.

[19] K.-p. Zhou, B. Li, J.-1. Li, H.-W. Deng, and F. Bin, "Microscopic damage and dynamic mechanical properties of rock under freeze-thaw environment," Transactions of Nonferrous Metals Society of China, vol. 25, no. 4, pp. 1254-1261, 2015.

[20] J.-l. Li, K.-P. Zhou, W.-J. Liu, and H.-W. Deng, "NMR research on deterioration characteristics of microscopic structure of sandstones in freeze-thaw cycles," Transactions of Nonferrous Metals Society of China, vol. 26, no. 11, pp. 2997-3003, 2016.

[21] Z. Pan, K. P. Zhou, R. G. Gao, J. Zhen, Y. Chun, and G. Feng, "Research on the pore evolution of sandstone in cold regions under freeze-thaw weathering cycles based on NMR," Geofluids, vol. 2020, Article ID 8849444, 12 pages, 2020.

[22] H. Cheng, H. Q. Chen, G. Y. Cao, C. X. Rong, Z. S. Yao, and H. B. Cai, "Damage mechanism of porous rock caused by moisture migration during freeze-thaw process and experimental verification," Chinese Journal of Rock Mechanics and Engineering, vol. 39, no. 9, pp. 1739-1749, 2020.

[23] T. Liu, Y. Wang, K. Zhou, F. Gao, and S. H. Xie, "Research on the mechanical properties and NMR characteristics of cement mortar during freeze-thaw cycles," Advances in Civil Engineering, vol. 2019, Article ID 6805480, 7 pages, 2019.

[24] X. Wang, X. Shen, H. Wang, C. Gao, and T. Zhang, "Nuclear magnetic resonance analysis of freeze-thaw damage in natural pumice concrete," Materiales de Construcción, vol. 66, no. 322, p. e087, 2016.

[25] X. Wang, Y. Wu, X. Shen, H. Wang, S. Liu, and C. Yan, “An experimental study of a freeze-thaw damage model of natural pumice concrete," Powder Technology, vol. 339, pp. 651-658, 2018.

[26] C. Y. Niu, Z. M. Zhu, L. Zhou et al., "Study on the microscopic damage evolution and dynamic fracture properties of sandstone under freeze-thaw cycles," Cold Regions Science and Technology, vol. 191, Article ID 103328, 2021.

[27] J. Zhang, H. Deng, J. Deng, and R. Gao, "Fractal analysis of pore structure development of sandstone: a nuclear magnetic resonance investigation," IEEE Access, vol. 7, pp. 4728247293, 2019.

[28] J. Li, R. B. Kaunda, and K. Zhou, "Experimental investigations on the effects of ambient freeze-thaw cycling on dynamic properties and rock pore structure deterioration of sandstone," Cold Regions Science and Technology, vol. 154, pp. 133-141, 2018.

[29] X. L. Shang, "Microstructure and Characterization of interfacial transition zone of hardened concrete," Sichuan Cement, vol. 2017, no. 8, pp. 268-269, 2017.

[30] M. Wang, Y. Xie, G. Long, C. Ma, and X. Zeng, "Microhardness characteristics of high-strength cement paste and interfacial transition zone at different curing regimes," Construction and Building Materials, vol. 221, pp. 151-162, 2019.

[31] X. Yang, A. Shen, Y. Guo, S. Zhou, and T. He, "Deterioration mechanism of interface transition zone of concrete pavement under fatigue load and freeze-thaw coupling in cold climatic areas," Construction and Building Materials, vol. 160, pp. 588-597, 2018.

[32] R. Xie, L. Lu, and P. Qiao, "Investigation on degradation of micromechanical properties of interfacial transition zone of ultra-high performance concrete under freeze-thaw cycles," Scientia Sinica Technologica, vol. 48, no. 10, pp. 1092-1102, 2018.

[33] W. G. Li, J. Z. Xiao, L. Huang, and Surendra, "Experimental study on mechanical properties of interfacial transition zones in recycled aggregate concrete," Journal of Hunan University, vol. 41, no. 12, pp. 31-39, 2014.

[34] J. Xiao, W. Li, Z. Sun, D. A. Lange, and S. P. Shah, "Properties of interfacial transition zones in recycled aggregate concrete tested by nanoindentation," Cement and Concrete Composites, vol. 37, pp. 276-292, 2013.

[35] J. Teng, F. Shan, Z. He, S. Zhang, G. Zhao, and D. Sheng, "Experimental study of ice accumulation in unsaturated clean sand," Géotechnique, vol. 69, no. 3, pp. 251-259, 2019.

[36] R. J. M. Pellenq, N. Lequeux, and H. Damme, "Engineering the bonding scheme in C-S-H: the iono-covalent framework," Cement and Concrete Research, vol. 38, no. 2, pp. 159-174, 2008.

[37] B. $\mathrm{Li}$ and W. Chen, "C-S-H development on molecular structure of calcium silicate hydrate gel," Journal of the Chinese Ceramic Society, vol. 47, no. 8, pp. 1095-1100, 2019. 
[38] I. F. Sáez del Bosque, W. Zhu, and T. Howind, "Properties of interfacial transition zones (ITZs) in concrete containing recycled mixed aggregate," Cement and Concrete Composites, vol. 81, pp. 25-34, 2017.

[39] Y. J. Shen, X. Wei, G. S. Yang, Y. Z. Wang, H. L. Jia, and H. Zhang, "Freeze-thaw degradation model and experimental analysis of rock-concrete interface bond strength," Chinese Journal of Rock Mechanics and Engineering, vol. 39, no. 3, pp. 480-490, 2020. 